\title{
Helianthus annuus as a natural host for Stemphylium vesicarium in Iran
}

\author{
M. Arzanlou • S. Khodaei • A. Babai-Ahari
}

Received: 9 May 2012 / Accepted: 7 October 2012 /Published online: 17 October 2012

(C) Australasian Plant Pathology Society Inc. 2012

\begin{abstract}
Sunflower leaf spot is one of the most common as well as important foliar diseases of this host in northern Iran. Stemphylium vesicarium was revealed to be one of the causal agents of sunflower leaf spot based on morphological and molecular characteristics. The identity of the species was confirmed using sequence data from the ITS rDNA region and glyceraldehyde-3-phosphate dehydrogenase ( $g p d$ ) gene sequences. Pathogenicity of the fungus was proven by inoculation of four-week-old sunflower plants (cv. Euroflor) under controlled conditions. This is the first report on the incidence of $S$. vesicarium on $H$. annuus anywhere in the world.
\end{abstract}

Keywords Sunflower · Leaf spot $\cdot g p d$ gene $\cdot$ ITS rDNA

Sunflower, Helianthus annuus L., a member of the Asteraceae, is grown mainly for edible oil production and confectionery use worldwide. Sunflower oil ranks fourth in world vegetable oil production (Anonymous 2010). Fungal leaf spot diseases are among the most prevalent and significant problems on sunflower in many sunflower-growing countries (Bhutta 1998). Several leaf spot- causing fungal species have been reported to occur on wild and cultivated sunflower plants, including A. zinniae Pape and Ellis, A. alternata (Fries) Keissler, A. tenuissima (Nees) Wiltshire, A. helianthicola Rao \& Rajagopalan, A. helianthinficiens Simmons, Walcz \& Roberts, A. protenta Simmons, Alternariaster helianthi (Hansford) Simmons, Septoria helianthi Ellis \& Kellerman, Septoria helianthina Petrov \& Arsenijevic, Cercospora bidentis Tharp, Cercospora helianthicola Chupp \& Viegas, Ascochyta compositarum Davis, Ascochyta helianthi Abramov, Cladosporium cladosporioides (Fresenius) de

M. Arzanlou $(\bowtie) \cdot$ S. Khodaei $\cdot$ A. Babai-Ahari Plant Protection Department, Faculty of Agriculture, University of Tabriz, P.O. Box: 5166614766, Tabriz, Iran

e-mail: arzanlou@hotmail.com
Vries, Curvularia lunata (Wakker) Boedijn, Drechslera helianthi Hulea, Phoma exigua Desmazieres, Phoma macdonaldii Boerema, Phoma helianthi Pachkhede, Vyawahare \& Shreem, Bipolaris spicifera (Bainier) Subramanian, Bipolaris zeicola (Stout) Shoemaker, Bipolaris spicifera (Bainier) Subramanian, Bipolaris zeicola (Stout) Shoemaker, Passalora helianthicola Braun \& Crous Passalora helianthi (Ellis \& Everhart) Braun \& Crous, Passalora pachypus (Ellis \& Kellerman) Braun, Colletotrichum helianthi Davis, Colletotrichum helianthicola Camara, Phyllosticta wisconsinensis Greene and Lasiodiplodia theobromae (Patouillard) Griffon \& Maublanc (Pandey and Saharan 2005). The aim of present study was to identify the causal agents of leaf spot of sunflower in northwest Iran. Herein we document a new leaf spot of sunflower in Iran.

A survey of leaf spots of sunflower during August-September 2010 in West Azerbaijan Province, Iran, revealed that Alternaria alternata was the most prevalent fungal species responsible for the disease. In field-grown plants in the Miandoab region, along with Alternaria leaf spots, lesions with a different appearance were also observed on nearly all plants. Leaf spots were circular to irregular, brown to dark brown in color, necrotic, surrounded with a yellow halo, 20-25 $\mathrm{mm}$ in diam., scattered all over the leaf blade and, in some cases, coalesced and formed large necrotic areas (Fig. 1). Samples from diseased specimens displaying severe leaf spot symptoms were collected. Sections of symptomatic tissues were surface-sterilized with $70 \%$ ethanol for $20 \mathrm{~s}$, rinsed in sterile distilled water, dried on sterile filter paper and plated on acidified $2 \%$ malt extract agar (MEA, Himedia, India). Plates were incubated at $25^{\circ} \mathrm{C}$ in the dark. Single-spore cultures were obtained using a spore suspension dilution method as described by Arzanlou and Bakhshi (2011). In brief, a mass of conidia were picked up from the surface of a fungal colony using a wetted sterile inoculation needle and a stereomicroscope, suspended in $10 \mathrm{ml}$ sterile distilled water and spread on $2 \%$ MEA. Plates 
Fig. 1 Leaf spot caused by Stemphylium vesicarium on sunflower plants. a leaf spot symptoms on naturally infected sunflower in field. b Leaf spot symptoms on four-weeks-old sunflower (Euroflor cultivar) leaves under greenhouse conditions seven days after inoculation with Stemphylium vesicarium
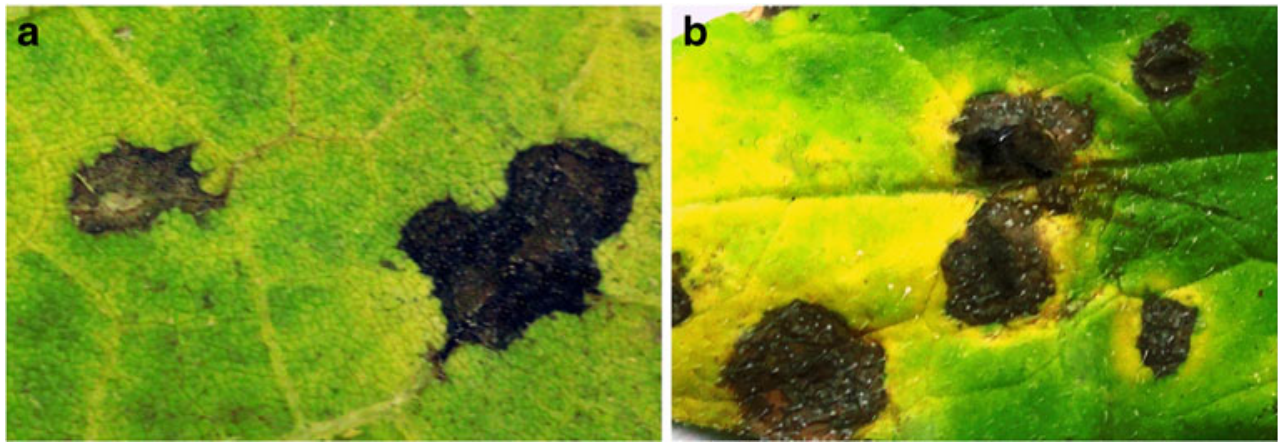

were incubated in an angled position overnight and germinated conidia were transferred to new MEA plates. Pure cultures were deposited in the Culture Collection of Tabriz University (CCTU) and Iranian Fungal Culture Collection (IRAN $2142 \mathrm{C}$ ). Cultural and microscopic features were studied on potato carrot agar (PCA; $20 \mathrm{gL}^{-1}$ potato, $20 \mathrm{~g}$ $\mathrm{L}^{-1}$ carrot, $20 \mathrm{gL}^{-1}$ agar) and held at $25^{\circ} \mathrm{C}, 40 \mathrm{~cm}$ from the illumination of cool white fluorescent bulbs with a light/ dark cycle of $8 / 16$ h daily for 7 days. Growth rate was recorded as the maximum diameter of colony after 7 days. Microscopic features were determined using lactic acid mounts. Measurements of all parameters were made at $\times 1,000$ magnification, with 30 measurements per structure. Photographs were captured with a Leica camera system (Fig. 2).

Fungal isolates were identified as Stemphylium vesicarium (Wallroth) Simmons (1969) based on morphological examination. In culture: colonies on PCA were grey to brownish grey, formed concentric rings, were flat, entire, and circular, attaining a diameter of $50 \mathrm{~mm}$ after 7 days, with sparse aerial mycelium. Mycelium was immersed and superficial, subhyaline to pale brown, branched, septate, smooth, and 4$6 \mu \mathrm{m}$ diam. Conidiophores were macronematous, mononematous, scattered, un-branched, straight or flexuous, cylindrical, smooth, septate, pale to mid brown, (30-) 47-52 (-67) $\times 4$ $5 \mu \mathrm{m}$. Conidiogenous cells were monoblastic, integrated, terminal, swollen, dark brown, 6-7 $\mu \mathrm{m}$ diam, with up to 3 proliferations. Immature conidia were ellipsoid, rounded at the ends, mature conidia were $20-24(-30) \times 12-15 \mu \mathrm{m}$, with length/width ratios approaching 1.5-2.3, solitary, acrogenous, oblong to broadly ellipsoid, sub-truncate basally, rounded to sub-truncate apically, golden-brown to olive-brown, with 1-3 transverse and 1-4 longitudinal or oblique septa, often constricted at one or more of the septa, cicatrized at the base, with a verrucose conidial wall. After about 2 months, mature perithecia were visible in the cultures: Perithecia were superficial or sometimes completely or slightly immersed in the agar, gregarious, black, spherical to sub-spherical, rostrate, up to $500 \times 1,000 \mu \mathrm{m}$; the neck was usually $25 \mu \mathrm{m}$ long. Asci were cylindrical, short-stalked, thick-walled, 8 -spored, and up to $180 \times 45 \mu \mathrm{m}$. Mature ascospores were yellowish brown, oblong-ovoid, obtuse basally, domical apically, (32-) 34-36
$(-40) \times 14-17 \mu \mathrm{m}$, wider in the upper half with 7 transverse and numerous longitudinal septa, more or less constricted at the septa, uniseriate to slightly overlapping, with the 3 main transverse septa thickened, darkened and more constricted (Fig. 2).

The identities of the isolates were further confirmed using sequence data of the internal transcribed spacer (ITS) region of rDNA and partial sequence of the Glyceraldehyde-3-phosphate dehydrogenase $(g p d)$ gene. Genomic DNA was extracted using the method of Moller et al. (1992). The primers ITS1 and ITS4 (White et al. 1990) were used to amplify the ITS rDNA of the nuclear ribosomal RNA operon, including: the 3 ' end of the 18S rRNA gene, the first ITS (ITS1), the 5.8S rRNA gene, the second ITS (ITS2) and the $5^{\prime}$ end of the 28S rRNA gene. The reaction mixture and PCR conditions were the same as described by Arzanlou and Khodaei (2012). The gpd gene was amplified with primers gpd1 and gpd2 (Berbee et al. 1999). The PCR assay was carried out in a final volume of $12.5 \mu \mathrm{l}$ containing $10-15 \mathrm{ng}$ genomic DNA, $1.25 \mu \mathrm{l}$ of $10 \times$ reaction buffer, $60 \mu \mathrm{l}$ of $1 \mathrm{mM}$ dNTPs, $1 \mathrm{mM} \mathrm{MgCl} 2,0.2 \mathrm{pM}$ of each primer, $0.5 \mu \mathrm{l}$ DSMO, and $0.5 \mathrm{U}$ Taq Polymerase. The reaction was performed on a GeneAmp PCR System 9700 (Applied Biosystems, Foster City, CA) with cycling conditions consisting of $5 \mathrm{~min}$ at $96{ }^{\circ} \mathrm{C}$ for primary denaturation; followed by 40 cycles of $94{ }^{\circ} \mathrm{C}$ for $30 \mathrm{~s}, 57{ }^{\circ} \mathrm{C}$ for $30 \mathrm{~s}$, $72{ }^{\circ} \mathrm{C}$ for $30 \mathrm{~s}$; with a final extension at $72{ }^{\circ} \mathrm{C}$ for $7 \mathrm{~min}$. The amplicons were sequenced using BigDye terminator kit (Amersham Biosciences, Freiburg, Germany) and analysed on an ABI Prism 3700 (Applied Biosystems, Foster City, CA) under conditions recommended by the manufacturer. Homology searches were performed using the NCBI Blast search. BLAST searches analyses showed that the sequence data for both loci are identical to those of $S$. vesicarium, $S$. herbarum Simmons, $S$. botryosum Wallroth and $S$. alfalfae Simmons from GenBank. The sequences were deposited into GenBank (ITS: Accession No. JX424810, JX424811, JX424812 and JX424813; gpd: Accession No. JX424814 and JX424815).

Koch's postulates were performed using a selected isolate grown on PCA for 7 days. Sunflower plants (cultivar Euroflor) were planted in plastic pots containing a 1:1:1 ( $\mathrm{vol} / \mathrm{vol} / \mathrm{vol})$ 


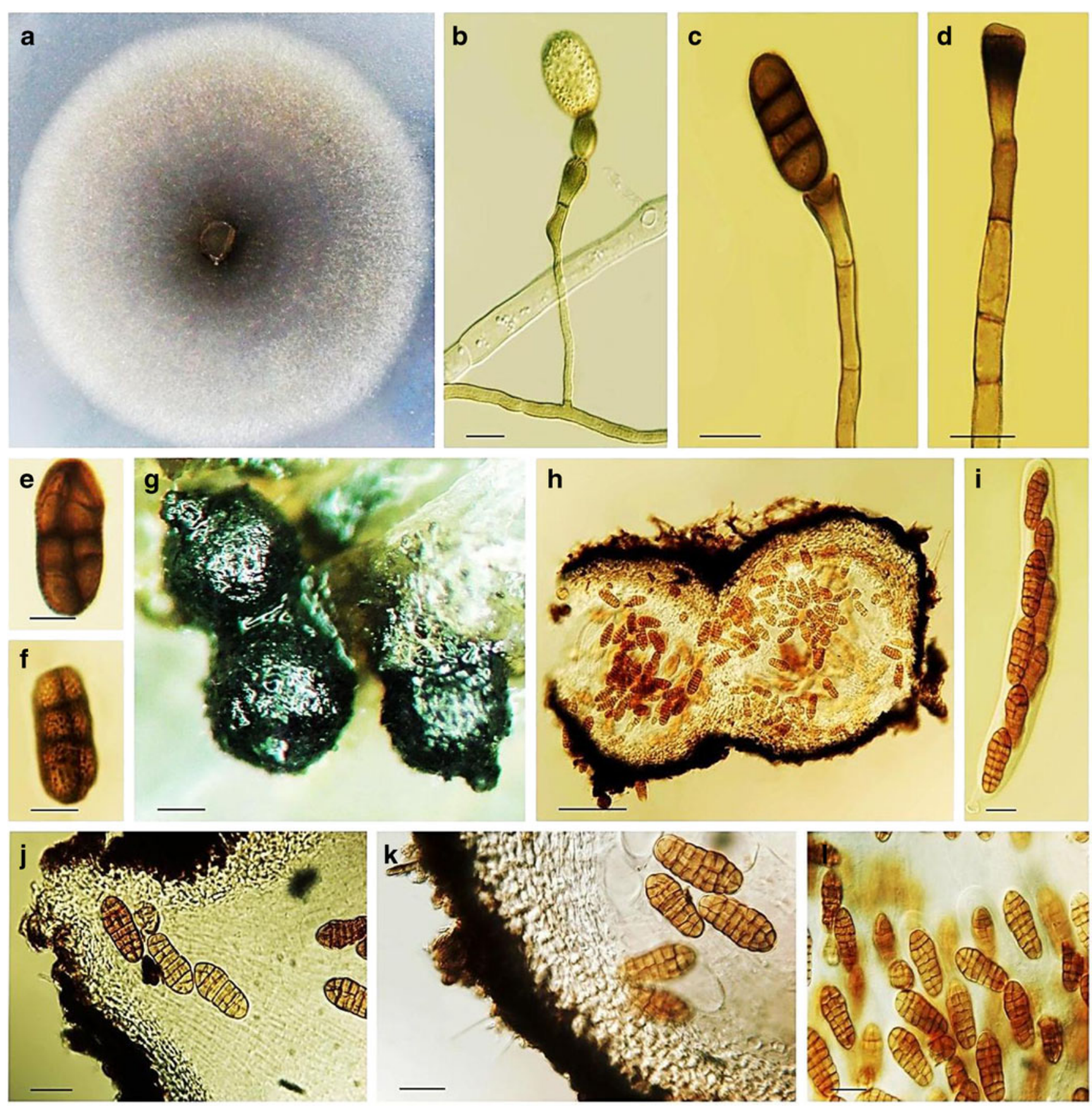

Fig. 2 Stemphylium vesicarium. a Colony on PCA. $\mathbf{b}-\mathbf{f}$ Conidia and conidiophores. $\mathbf{g}$ Perithecia. $\mathbf{h}, \mathbf{j}, \mathbf{k}$ Cross section of perithecia. $\mathbf{i}, \mathbf{l}$ Asci and ascospores. Bars $(\mathbf{b}-\mathbf{f})=10 \mu \mathrm{m},(\mathbf{g}-\mathbf{h})=200 \mu \mathrm{m}, \mathbf{i}-\mathbf{l}=20 \mu \mathrm{m}$

mixture of pasteurized soil, perlite and peat, grown for 4 weeks in a greenhouse maintained at $30^{\circ} \mathrm{C}$ with a 16 -h photoperiod, before inoculation. Three plants were sprayed with a conidial suspension at $10^{5}$ conidia per $\mathrm{ml}$. Control plants (three plants) were sprayed with distilled sterile water. Inoculated plants were incubated in moist chamber for $48 \mathrm{~h}$. Inoculated plants were inspected for the disease symptom development daily for 10 days after inoculation. To satisfy Koch's postulates, symptoms developed on in vitro inoculated leaves were compared with original symptoms. Under greenhouse conditions, the fungus induced the same symptoms as in the fields (Fig. 1). Symptoms appeared as scattered spots over the whole leaf. Symptoms appeared 3-4 days after inoculation on the older leaves, as dark brown to tan-colored spots that turned greyish black and developed a yellow hallo. The spots coalesced and leaves eventually withered and died, leading to complete leaf shedding. Some lesions became black when conidia were produced. Defoliation was the marked symptom in the 
advanced stage of infection. Control plants did not develop any symptoms. The fungus was re-isolated from the inoculated leaves, but not from tissues of any of the control plants, thus proving the pathogenic nature of the fungus inoculated.

Stemphylium leaf blight caused by Stemphylium vesicarium occurs on a number of plant species, and is widespread in Asia and Europe. It has been reported from plants such as Allium L. spp., Asparagus officinalis L., Pyrus communis L. (Kumar 2007), and Hordeum vulgare L. (Ershad 2009). Species of the genus Stemphylium commonly colonize dead plant materials; such that, there is a paucity of knowledge on the host-specificity of Stemphylium spp. The results of a recent study on the pathogenicity of Stemphylium vesicarium isolates recovered from different host plant species, on pear have shown that only the isolates from pear orchard including pear fruits, dead pear leaves, dead grass leaves present in pear orchard were pathogenic on pear; while, the isolates from onion and asparagus were not pathogenic on pear (Köhl et al. 2009). Analysis of genetic variation amongst Stemphylium vesicarium isolates from different host plants has clustered the isolates from pear orchards in a separate cluster (Köhl et al. 2009). There are some data available that host-specific toxins produced by Stemphylium vesicarium from pear may play a role in the pathogenicity of the isolates on this host (Singh et al. 1999). To the best of our knowledge, this is the first report of the pathogenicity of $S$. vesicarium on sunflower anywhere in the world. The identity of isolates was confirmed using the ITS and $g p d$ sequence data. Sequence data of these two loci in $S$. vesicarium isolates were identical to those of S. botryosum, $S$. alfalfae and $S$. herbarum. The data were in concordance with the results of Inderbitzin et al. (2009) for whom a phylogeny inferred from multiple gene sequences data, failed to resolve phylogeny of the Pleospora species with Stemphylium anamorphs in Pleospora herbarum clade viz., S. botryosum, S. alfalfae and S. herbarum (Inderbitzin et al. 2009). However, morphological features of the sunflower isolates are in agreement with the description of $S$. vesicarium. Simmons (1969) has discussed the morphological similarities of these taxa in detail. S. vesicarium is readily distinguishable from the other three species on the basis of the time needed to produce mature ascocarps, shape of juvenile conidia, number of constricted septa on the conidia, conidial dimensions, length/ width ratios of conidia and size of asci (Simmons 1969).

The finding that $S$. vesicarium can infect $H$. annuus is interesting ecologically given that the potential for infection of new host has been developed in S. vesicarium isolates, which probably required adaptation to a unique environment. Whether the pathogenicity of $S$. vesicarium from sunflower is restricted to this host, or they can infect other plants as well remains to be tested. Additional work is needed to explorer the distribution of the causal agent and the impact of the disease on sunflower crop production.

Acknowledgments The authors would like to thank the Research Deputy of the University of Tabriz and the Studienstiftung Mykologie, for financial support.

\section{References}

Anonymous (2010) Agribusiness handbook: sunflower crude and refined oils. FAO/EBRD, Rome

Arzanlou M, Bakhshi M (2011) Microcyclospora rumicis, a new species on Rumex crispus from Iran. Mycotaxon 118:181-186

Arzanlou M, Khodaei S (2012) Phenotypic and molecular characterization of Chaetopyrena penicillata from Iran with description of a hyphomycete synanamorph. Mycosphere 3:73-77

Berbee ML, Pirseyedi M, Hubbard S (1999) Cochliobolus phylogenetics and the origin of known, highly virulent pathogens, inferred from ITS and glyceraldehyde-3-phosphate dehydrogenase gene sequences. Mycologia 91:964-977

Bhutta AR (1998) Biological studies on some fungi associated with sunflower in Pakistan. PhD Thesis, Sindh Agriculture University, Tandojam, Pakistan

Ershad D (2009) Fungi of Iran, 3rd edn. Iranian Research Institution of Plant Protection, Tehran

Inderbitzin P, Mehta YR, Berbee ML (2009) Pleospora species with Stemphylium anamorphs: a four locus phylogeny resolves new lineages yet does not distinguish among species in the Pleospora herbarum clade. Mycologia 101:329-339

Köhl J, Molhoek WML, Groenenboom-de Haas BH, Goossen-van de Geijn HM, Speksnijder A, Kastelein P, de Hoog S, Gerrits van der Ende AHA (2009) Pathogenicity of Stemphylium vesicarium from different hosts causing brown spot in pear. Eur J Plant Pathol 151:124-142

Kumar P (2007) Genetics of resistance to Stemphylium leaf blight of lentil (Lens culinaris) in the cross Barimasur- $4 \times$ CDC Milestone. MSc Thesis, University of Saskatchewan, Saskatoon, Canada

Moller EM, Bahnweg G, Geiger HH (1992) A simple and efficient protocol for isolation of high molecular weight DNA from filamentous fungi, fruit bodies, and infected plant tissues. Nucl Acid Res 20:6115-6116

Pandey RN, Saharan GS (2005) Facultative fungal disease of sunflower. In: Saharan GS, Mehta N, Sangwan MS (eds) Disease of oilseed crops. Indus Publishing Company, Delhi

Simmons EG (1969) Perfect states of Stemphylium. Mycologia 61:126

Singh P, Bugiani R, Cavanni P, Nakajima H, Kodama M, Otani H, Kohmoto K (1999) Purification and biological characterization of host-specific SV-toxins from Stemphylium vesicarium causing brown spot of European pear. Phytopathology 89:947-953

White TJ, Bruns TD, Lee SB, Taylor JW (1990) Amplification and sequencing of fungal ribosomal RNA genes for phylogenetics. In: Innis N, Gelfand D, Sninsky J, White TC (eds) PCR protocols and applications - a laboratory manual. Academic, New York 